\title{
How to manage the evolution of a computerized information system
}

\author{
JOHN DOW and DAVID JAKIELO \\ Western Psychiatric Institute and Clinic, University of Pittsburgh School of Medicine \\ Pittsburgh, Pennsylvania 15261
}

\begin{abstract}
Existing computerized fiscal and patient information systems do not seem well suited for the mental health field. To design its own system, an institution would do better to form an information system staff rather than to use an outside software house, because doing it externally is less responsive, slower, and, for some tasks, simply impossible. The in-house staff must be selected to be competent generalists, at ease with computer technology. Working in close and friendly cooperation with various user groups, the systems evolve out of small beginnings. As the users gain working experience with early versions of a system, they are able to refine their goals, with the result that the final system meets their needs well, even though it may seem to be different from what was originally expected.
\end{abstract}

Commercially available fiscal and patient information systems seem better suited for meeting the needs of the general, acute care facility than for meeting the idiosyn. cratic billing, patient-tracking, and reporting needs of the mental health facility. Many mental health facilities have therefore not computerized or have attempted to force themselves into the mold provided by shared hospital systems. Following the guidelines described below, we at the Western Psychiatric Institute and Clinic have been able to develop our own system. A basic idea frequently used was to duplicate our manual procedures on the computer and then to let a totally computerized system evolve one step at a time. By allowing a system to evolve in this way, it is not necessary to plan the final system in any detail; a conceptual grasp of the overall direction is sufficient.

\section{SYSTEM DEVELOPMENT METHODOLOGIES}

If there is no existing shared or stand-alone software package to meet the needs of an institution, there is the possibility of going to a custom software house to have one developed. Typically, both parties in such cases want to avoid an open-ended contract. The software house does not want to accept liability for an unknown product at a fixed fee, but the institution does not want an unknown fee. Therefore, the standard procedure is to define the product and fee in some detail before beginning actual development.

While this approach seems clean, it suffers from a very serious drawback in those system development situations to which this paper is addressed, namely, those in which the system designers quite literally are unable to specify what the final system will look like. This inability stems from the fact that these systems are themselves complex and, furthermore, that they must operate in a service-oriented health care facility with its myriad daily, global, and political issues. Without having already developed a system in an essentially identical institution, a designer could not be expected to forecast just how each of the many forces will interact. Therefore, it could easily happen that the institution would define the system and have it completed on schedule for the agreed-upon fee only to learn that the institution's own specifications were inappropriate. The conclusion seems inevitable that the system development process must somehow remain open-ended.

For an institution to expect to develop a system under these conditions requires a commitment different from that required with a well-defined contract. In some instances, it may be possible to establish a good working relationship with an outside firm that is willing to work with the open-ended situation, but we suspect that usually, the institution would be better off to have in-house staff do the work. Although the costs of equipment and staff are greater when the work is done in-house, these costs can be more than offset by a shorter timetable for modifications and by not having to pay the high labor rates for custom work. This article will give some guidelines for how this in-house staff and its administrators should proceed. We can say from direct experience that many requests that can be handled routinely in-house would not even be considered as requests to be given to an outside vendor. The poorer responsiveness and the inability to invoke a higher authority from within the same organization to set priorities are not merely an inconvenience but, instead, are factors that make many problems literally impossible to solve.

\section{BRIEF HISTORY}

In order to provide a context for this paper and to let the reader understand the experience base from which we have drawn many of our conclusions, we briefly 
outline the history of our system development. We started by going on-line with a computerized master patient index in September 1976, providing a service to the admitting office and to medical records. In July 1977 , we began to produce patient bills, benefitting our patients and the fiscal programs by timely, accurate, and informative bills. Over the next couple of years, we added the reports necessary for the complete management of patient accounts. During this period, the staff of the billing office was reduced from 10 to 5 employees and receipts from patients and third-party payers increased. We also began using the computer to interface with the county by reporting, on tape, patient services provided under the community mental health program.

In its infancy, the development of the system was directed toward meeting fiscal requirements. Starting in the fall of 1979, we began restructuring parts of the system with the intent of being able to meet some of the hospital's administrative and clinical needs as well. Since then, the Diagnostic and Evaluation Center (which is both the assessment center and the emergency service for our hospital), medical records, and the admitting office have been using the computer on-line to determine the detailed service history of our patients, to identify their current clinician, and so forth. In January 1980, we began to generate several administrative reports. These include (1) a one-page summary report for each clinic (which gives a monthly snapshot of caseload, utilization, reporting delay problems, and fiscal status), (2) a listing of active patients (alphabetized by clinician within clinic and showing last professional contact or visit, degree of activity, and current billing status), and (3) a listing of clinicians (with number of contacts, cases, and hours of service for each clinic in which the clinician provided service). The unique feature of these reports is the juxtaposed presentation of fiscal and case-load data, thus helping to keep administrators and clinicians aware of all facets of the care and management of the large outpatient populations seen at the community mental health center.

While this development was underway, a parallel effort was started in the fall of 1978. At that time, a committee was formed by the chairman of the Depart. ment of Psychiatry, with the goal of designing and then implementing a clinical information system. In mid-1979, an operational group composed of the director of a clinical program, a researcher, and the director of our information systems program began working on the design and implementation of standardized initial evaluation procedures and a form, the Initial Evaluation Form (IEF) (see Mezzich, Dow, \& Coffman, 1981, for a comprehensive discussion of the goals, methods, and current status of this effort). The IEF consists of a narrative and standardized clinical history and assessment section, together with the demographic and financial sections already in use. After much research and testing, the form, in a nearly finalized version, was put on our computer system for on-line entry and retrieval in August 1980. In September, we put the $\log$ of patient visits to our diagnostic and evaluation center onto the system. With the IEF and the log on-line, clinicians at any time of the day or night can obtain a patient's medical record number and extensive demographic, financial, and clinical information within minutes.

\section{OUR PLANS}

The software and procedures that we have had operational have, until very recently, been primarily oriented toward billing. However, the major thrust has recently been to develop a total mental health system, including patient-tracking reports, reports to help medical records and more reports for administrators and clinicians, and finally, to computerize a clinical information system with assessments and ratings by clinicians. The development of this last system is already well underway in the form of a carefully designed and tested form, the IEF mentioned above. The data are already being entered into our patient data system for on-line retrieval. Further computerization will make it possible to do such things as generate statistics, compute scale scores, and derive summary narratives from the standardized data (see Dow, 1975, for a description of the technical approach to be used for these tasks). We are fully confident that the same guidelines that we have been using will continue to work well in these ongoing efforts.

\section{THE BEGINNING-STAFF SELECTION}

For simplicity's sake, assume that an information systems staff must be formed in the hospital. To do this, the administrators must either select from existing staff or hire someone to run the information systems program. That person should have enough experience with the technology to be able to make appropriate decisions. Some managerial talent is also necessary, although support by administrators can help correct a deficiency in experience. The director of information systems would hire the additional staff. Because the information systems staff is supposed to come to the user, rather than vice versa, other programs would probably not have to hire anyone with experience with computers.

The most important contributions that administration can make toward the success of the system are (1) the selection of the system designers (i.e., the director of information systems and the key people in the user areas) and (2) their continued support once the project has begun. It is absolutely essential that these designers be proven problem solvers with the ability to communicate with people at all levels of the organization.

The size of the information systems staff must be small so that creativity is not stifled. But because it is 
small, it is important that the people chosen be competent generalists rather than highly trained specialists. By "generalist" we mean a person with high intelligence who is insightful and broad-minded, who enjoys actively participating in novel situations, and who has a sense of being able to understand and to do nearly anything he wants to do. Ramsgard (1977) likens the generalist to a general practitioner rather than a specialist. Some people have the proper temperament, attitudes, experience, and type of intelligence to be generalists, but it would be difficult to try to make someone a generalist who was not one already. Hence, the importance of proper selection of staff cannot be overstated.

Unfortunately, there does not seem to be an easy test to identify who the appropriate people are. From our experience, the best indicators would seem to be a high level of interest and intelligence, good verbal skills, good spatial awareness (i.e., the ability to mentally manipulate imaginary objects in space), analytical ability, and a demonstrated ease in handling the technology. Although a lot of experience is not an absolute necessity, sufficient work experience to demonstrate the above characteristics would be desirable.

\section{MANAGERIAL CONSIDERATIONS}

One of the reasons for having a small staff is to reduce the time required to manage it. However, a small group of people working closely together may be more likely to have personality clashes than a larger, more structured group. Some would argue that it is better to hire people who "fit in" and who will be easily managed rather than to hire those who would seem more able to contribute to the creative effort, but who may not fit in as well because they are unconventional individualists. We feel that the second route is worth the costs if the administrators (and other program heads) recognize the tradeoff and agree with it.

As part of the effort to reduce the managerial responsibilities of the director of information systems, we have placed data entry operations in user areas. If possible, each type of data should be entered in the area that is its heaviest user. This helps improve the quality of the data.

The information systems group works in a highly technical area about which people in general know very little and about which there are a number of misconceptions. For example, many projects that seem quite simple are, in fact, complex, and vice versa. While the administrator to whom the director of information systems reports should be expected to remain aware of technical progress in order to support the program at the management level of the organization, it is not essential for him to understand all the details. The directors and administrators of other programs should not be expected to understand much more than the order of priority. Because of these factors, the relation. ship between the information systems group and the rest of the hospital should be built carefully on openness. Those who handle the technology should never try to impress others with their skills and knowledge, but they should always attempt to help others understand as much as possible. The users of the system should feel that they are the peers of the designers of the system so that they can feel free to express their suggestions and criticisms. Openly soliciting ideas with a suggestion box sometimes works, although from time to time people need to be encouraged to use it. The designers should always be honest about their limitations and not try to appear infallible. In summary, informality and honesty are the keys to productive relations between designers, program heads, administrators, and users.

The productivity of the information systems staff should be examined from time to time. Given the marginal level of understanding by those not in the field, this can be a sore issue if not handled properly. Openness helps, as does a "to do" list. This is simply a listing of requested projects, ordered by date and identifying the requesting party. This list is available to anyone who is interested. Information systems staff members should also be sensitive to their image and visibility and try to schedule projects so that long periods of time working on important but poorly visible tasks are punctuated with perhaps relatively trivial but more noticeable tasks. The bottom line regarding productivity is answered in the long run by the performance of the programs. In the short run, it cannot be answered satisfactorily, and good working relations between the various program heads based on trust and cooperation must suffice.

It would be unrealistic to expect everyone who must interact with the computer technology to develop any significant level of understanding of it. However, there is great value in having someone from the user areas who is sympathetic to the "computer types." Although this person need not know much about the technology at the beginning, after a close and friendly working relationship has developed, he can be expected to have a feel for what is realistically achievable. This person can be invaluable at times when there is confusion about performance or expectations.

It is helpful in a variety of ways to have a monthly meeting of administrators, managers, and supervisors of areas that use the computer system. Primarily, this provides a means to inform users of what others expect of the system and how that might help or hinder them. Without this type of educational experience, people frequently forget that they are sharing a resource with others. The meeting is also a good place to discuss progress (or lack thereof), new hardware, gripes, and even some totally unrelated issues. The emphasis is sharing of knowledge; problem solving in the group should rarely be attempted, although a subcommittee could be formed of the relevant people for such ends. 


\section{THINK SMALL, GO SLOW}

Brooks (1975), in his entertaining book The Mythical Man-Month, argues convincingly that software projects can progress only at a particular pace, regardless of the size of the staff dedicated to the project. Furthermore, the optimum size of the staff should be very small if the task is complex. The small staff minimizes the adverse impact of the required communication and coordination needs. Since the design and implementation of a mental health information system is complex, it follows that the staff of the information systems program should be small. For several years, our staff size was two people, including the director of the program. As of this writing, we have grown to include four people.

There should be at most two or perhaps three people assigned to any one project. These individuals should be from different areas and should be charged with the responsibility of system evolution and be given essentially free rein for system development. It is good to have people from different areas involved, in order to provide different perspectives to improve problem solving ability and to reduce the likelihood of design errors. As needed, these people will draw upon others, sometimes by means of committees and scheduled meetings, but much more frequently on a more informal basis.

Even though a small staff is best and will be more productive than a large one, there clearly is a limit to its productivity. Therefore, it is necessary to explicitly focus the efforts of the group. A clear set of long-range goals is the first requirement. The willingness to adhere to goals and to not be sidetracked by special requests is the second.

Go slow. Some examples of going slow follow. (1) Avoid using temporary help to enter a massive data base from your manual systems, because the error rate is likely to be unacceptable. Use your regular staff to load active records first, letting the data base grow as needed. (2) Gradually make the transition from a totally manual to a computerized system. This will be more acceptable to staff and easily will allow for staff reduction through attrition. (3) Do not try to please everyone. Select a minimal number of tasks to address at any given time.

\section{PRIORITIES}

Going slow means that priorities must be used to decide what to do first. Establishing priorities is usually a difficult task. When the decision is made to computerize, every user considers his needs to be top priority. Some suggestions for setting priorities are the following. (1) Allow users to submit proposals and have them prioritize each as to top, middle, or low. Next review with each user the goal he or she hopes to achieve; sometimes the information provided on an already existing report will meet the need, or one can be slightly modified. If the review shows that the request is appropriate, it is placed on the master "to do" list, where it is available for all other users to examine. (2) Determining whether a request is appropriate is an educational process, especially for the users. They must learn to determine whether computerization is more efficient than a manual system, what impact the additional work load would have on the rest of the system, what may have to be given up to provide the new service, and what implementation of the request would contribute to the overall system goals.

\section{STEPS IN PROJECT IMPLEMENTATION}

There are certain logical steps to turn an idea into reality. Depending on the complexity of the idea, it may be necessary to use tools such as pilot testing, surveys, or parallel testing; however, the basic steps remain the same: (1) The designers get a working understanding of the task. This is done by having meetings with administrators, specialists, and the users that will be affected by the project. The meeting or meetings can be very informal. Helpful ideas and opinions can sometimes be obtained in very brief and informal encounters, such as with a phone call, or even at chance encounters, such as in the hall or lunchroom. The designers should listen seriously to any suggested solutions. However, most users are not well trained in problem solving techniques and, hence, are hard put to define the problem itself, let alone solve it, without skillful interviewing by the designers. (2) The designers retreat to put together a system that meets the basic needs, but which is planned to be expandable to meet subsequent needs. (3) The basic system is presented to the group in semicomplete form, so further suggestions can be heard. Those that are critical are discussed for immediate inclusion into the system. Here, "critical" means that the change must be made for the initial system to be acceptably functional and useful. Suggestions for other changes are added to the "to do" list for later review. It is amazing how many things can be deleted from a "to do" list later on, after people have used the system and change their ideas and priorities based on experience. At this time, concrete examples are extremely valuable in eliciting the understanding that users often have, even though they cannot express themselves fluently. Frequently, the designer comes to understand the task by having the faults in his proposed solutions pointed out by users, who, due to human nature, find it easier to see what is wrong than what is right. (4) The basic system is put into use. (5) The system is never considered complete. Planned, periodic reviews should be included in the initial design plans and followed up under the direction of the designers.

\section{INVOLVE THE END USER}

We believe strongly that end users should be involved in very real ways if the system is to work successfully. 
The simple fact that people think and feel can work for or against the system. It will work against the system if the user does not understand a task (and does not feel free to ask for clarification) or perhaps does not understand its importance. In these cases, the user will probably do what he thinks will "pass." On the other hand, if the user understands the task, understands its importance, feels free to ask questions and to offer suggestions, and in general feels "good" about the system, his adaptive powers will be used to help the system succeed, even if there are design defects or if abnormal situations arise.

The choice is with the designer to see that the users work for the system rather than against it. The designers (and their administrators) must be sensitive to the humanness of the end users. Relevant training in the social sciences and having been an end user oneself can both help this sensitivity.

\section{KEEP IT SIMPLE AND CLEAN}

Whenever there is a decision between a simpler and a more complex alternative, try to go with the simpler one. If it turns out that the decision was wrong, it is easier to build a simpler solution into a more complex one than it is to reduce a more complex solution down to a simpler one. Also, there is less potential for wasted effort, and the user has a visible, useful product in less time.

Programmers sometimes resort to quick solutions to problems, particularly if a strict time constraint has been imposed. Depending on the situation, such a solution may be entirely appropriate. However, if the program is to continue to be used, it will have to be cleaned up, or else a high price will be paid at some future time when the program requires maintenance. Similarly, operational procedures can be established quickly or time can be spent to develop a cleaner routine. For example, a normal file copy operation may be performed initially by using a general-purpose utility program (which requires the operator to supply several parameters). In time, a more automatic procedure should be developed to reduce the probability of error.

There is an apparent paradox in the use of quick solutions; they both help and hurt the credibility of the system architects. They help because the developers can be more responsive in a particular situation, but they hurt because time is required to clean them up later and there may be no visible indicator of productivity during the clean-up phase.

A final point is that the older a system is, the more important this consideration becomes, due to the increased cost of recovery once a problem is discovered. For instance, with time, there are likely to be more users running more programs accessing larger data files than there were in the early stages of the system. For these reasons and because the computer system is used to greater capacity, the down time and recovery effort are greater.

\section{CONCLUSION}

We have not attempted in this article to indicate specifically what to do to design an information system, for the simple reason that each situation is different. Rather, we have tried to share the attitudes and expectations that make a successful system possible. With the proper approach, proper people, and patience, it is possible to develop systems not otherwise available.

\section{REFERENCES}

Brooks, F. P., JR. The mythical man-month. Reading, Mass: Addison-Wesley, 1975.

Dow, J. T. Designing computer software for information systems in psychiatry. Computers and Biomedical Research, 1975, 8, 538-559.

Mezzich, J. E., Dow, J. T., \& Cofrman, G. A. Developing an efficient clinical information system for a comprehensive psychiatric institute. Behavior Research Methods \& Instrumen. tation, 1981, 13, 459-463, 464-478.

Ramsgard, W. C. Making systems work. New York: Wiley, 1977. 